\title{
Perfil Sazonal dos Enterococcus e Escherichia coli nos mananciais do Distrito Federal
}

\author{
Ana Flavia Correia Heringer ${ }^{1}$ \\ Patricia Fernanda Batista Santos ${ }^{2}$ \\ Valdi Lopes Tutunji ${ }^{3}$
}

\section{Resumo}

Para avaliar a eficácia de um indicador microbiológico, não basta verificar sua ação como fato isolado. $\mathrm{O}$ ambiente externo tem seu papel designado de acordo com as variações climáticas. No Distrito Federal, duas estações são aparentes: o período da seca e da chuva. O objetivo deste trabalho é analisar os valores obtidos, ao aplicarem-se as técnicas do substrato enzimático para E. coli e dos tubos múltiplos para Enterococcus, comparando-os para se obter aquele que se apresenta como melhor indicador de contaminação e determinar a influência do clima sobre a população de bactérias presentes nos mananciais. Valores demonstraram que os Enterococcus foram tão ou mais resistentes à ação do meio externo que a $E$. coli, embora não se possa concluir que exista um indicador mais eficaz. A avaliação sazonal determina quando podemos utilizar os indicadores, devido às adversidades do meio, conferindo mais segurança para a qualidade da água e, conseqüentemente, para a saúde humana.

Palavras-chave: Recursos hídricos. Microbiologia ambiental. Enterococcus.

\footnotetext{
${ }^{1}$ Faculdade de Ciências da Educação e da Saúde. Centro Universitário de Brasília - UniCEUB. Bolsista Voluntária. email: anaheringer@gmail.com

${ }^{2}$ Faculdade de Ciências da Educação e da Saúde. Centro Universitário de Brasília - UniCEUB. email: patriciafbsantos@yahoo.com.br

${ }^{3}$ Faculdade Atenas - Paracatu. email: microbiologia@antibios.com
} 


\section{Introdução}

O equilíbrio entre o homem e a natureza, hoje, deixa para trás a cultura do uso infinito de recursos naturais e prioriza a ação sustentável, mobilizando os profissionais da saúde e a comunidade a participar, valorizar e cooperar.

A água constitui um destes elementos fundamentais para a existência do homem. Suas funções no abastecimento público, industrial e agropecuário, na preservação da vida aquática, na recreação e no transporte demonstram essa importância vital (HACHICH et al, 2000).

A preservação da qualidade da água é uma necessidade universal que exige séria atenção por parte das autoridades sanitárias e órgãos de saneamento, principalmente em relação às captações e águas destinadas ao consumo humano, visto que sua contaminação por fezes de origem humana ou animal pode torná-los um veículo na transmissão de agentes de doenças infecciosas e parasitárias. Este é um dos maiores motivos de preocupação do homem devido a intensa atuação e impacto na qualidade da água, assim como seu uso e ocupação (VON SPERLING, 1996).

A questão da água não se resume somente a sua conseqüente escassez em várias partes do mundo, mas também, ao desperdício e à poluição das fontes de abastecimento. A falta de saneamento é um fator agravante da poluição nos mananciais, tanto do ponto de vista da agressão ao meio ambiente quanto de saúde pública.

A preocupação com a preservação das captações também é de importância para qualidade pré-tratamento. As águas brutas ou in natura são transportadoras de todos os elementos presentes em suspensão no corpo d'água tais como matéria orgânica e produtos tóxicos, por isso se faz necessário o monitoramento do manancial.

Se a quantidade de matéria orgânica é grande e a poluição das águas é alta, uma série de processos será alterada havendo muito alimento à disposição como proteínas, aminoácidos, carboidratos, gorduras e conseqüente proliferação dos microorganismos presentes, tais como, o Enterococcus e a E. coli, entre outros. 
A análise de indicadores bacterianos na água é um método bastante sensível e específico para detecção de poluição biológica. Os indicadores de contaminação fecal estão presentes em grandes quantidades nos dejetos de animais homeotérmicos e apresenta persistência em ambiente aquático. Somente pessoas ou animais infectados eliminam esses microorganismos, que podem estar em concentrações extremamente baixas nas amostras de água (YOSHPE, 1989; FIGUEIRAS et al, 1996). Por esse motivo se considera contaminada a água que contenha bactérias indicadoras de poluição fecal, devido ao risco da presença de microorganismos enteropatogênicos (HACHICH et al, 2000; TORTORA; FUNKE; CASE, 2002).

A escolha dos indicadores deve levar em consideração: a presença em grande quantidade nas fezes humanas, a persistência e resistência no ambiente aquático e ser quantificável por métodos laboratoriais rápidos, simples e de baixo custo. Assim para a análise laboratorial, hoje, o indicador mais utilizado é a E. coli. Ressaltese que a ausência dessa bactéria não comprova a inexistência de outros microorganismos patogênicos (TORTORA; FUNKE; CASE, 2002).

$\mathrm{O}$ fato dos coliformes termotolerantes serem pouco resistentes ao ambiente e às ações naturais do meio, como a chuva e a estiagem faz com que haja discussões sobre a relevância de se haver apenas um indicador de contaminação fecal para a análise de qualidade da água em mananciais. Sugere-se então que não somente um, mas dois ou mais indicadores possam revelar o índice de contaminação dessas captações, onde a união desses dados proporciona um melhor monitoramento sanitário. A legislação brasileira é flexível quanto à escolha do indicador, ficando a critério do laboratório a escolha daquele que lhe for mais acessível. Recomenda-se a análise de coliformes termotolerantes ou a análise de E. coli.

Cabe ressaltar que a qualidade das águas muda ao longo do ano em função de fatores meteorológicos e da eventual sazonalidade de lançamentos poluidores e das vazões. A influência das chuvas, por exemplo, retira o sedimento presente no fundo dos rios e lagos (zona bêntica) e o move para a zona litorânea, onde há a penetração de luz e abundância de oxigênio.

Além de informações sobre a presença de contaminação fecal na água, as análises microbiológicas são úteis para avaliar a eficácia dos métodos de tratamento, assim como preservar a saúde da população. Faz-se, diante do ex- 
posto, necessário comparar as metodologias microbiológicas e os resultados obtidos, empregados pela Companhia de Saneamento Ambiental do Distrito Federal (CAESB) em mananciais de captação de água, e avaliar qual indicador microbiológico é mais eficaz, quando se trata de contaminação fecal por animais homeotérmicos, de acordo com a estação do ano, visando objetivar a relação existente entre chuva, seca e microorganismos.

\section{Material e métodos}

Para a análise microbiológica dos Enterococcus e E. coli, foi realizado um estudo descritivo longitudinal de corte nas regiões administrativas do Distrito Federal. Foram selecionados os mananciais de captação de água e as análises realizadas, no período de junho de 2006 a maio de 2007. Foram coletadas vinte e oito amostras das pequenas captações do Programa de Monitoramento das Captações da CAESB.

Para a determinação do número de E. coli nas amostras coletadas foi utilizada a técnica do substrato cromogênico definido ONPG-MUG (COLLILERT/QUANTI-TRAY ${ }^{\circ}$ ), de acordo com as recomendações do fabricante e do Standard Methods for the Examination of Water and Wastewater (APHA/ AWWA/WEF, 2005).

Foram transferidos $100 \mathrm{ml}$ da amostra para uma proveta estéril, depois para outro frasco de coleta estéril, e adicionou-se um frasconete de COLILERT $^{\bullet}$. Homogenizou-se até a sua perfeita dissolução e em seguida se transferiu a amostra para a Cartela Quanti-Tray 2000, que foi selada e incubada a $35,0 \pm 0,5^{\circ} \mathrm{C}$ para quantificação bacteriana, após período de incubação de $24 \mathrm{~h}$ $+4 \mathrm{~h}$.

No sistema Colilert, a presença de E. coli é indicada por meio das células da Cartela Quanti-Tray 2000 que apresentaram coloração amarelada e que após submissão à luz U.V. emitiram fluorescência azul, sendo quantificada por tabela estatística do Número Mais Provável - NMP do sistema Quanti-Tray 2000.

Para a determinação do Enterococcus foi utilizada a técnica dos tubos múltiplos, de acordo com as recomendações do Standard Methods, $21^{\text {a }}$ ed. mé- 
todo 9221, onde se inoculou a amostra bruta em tubos contendo meio de cultura para enriquecimento e proliferação das colônias (Difco ${ }^{\mathrm{TM}}$ Azide Dextrose Broth - Cat. No. 238710, com indicador de pH - Azul de Bromotimol) .

Estes tubos foram incubados a $35,0 \pm 0,5^{\circ} \mathrm{C}$ por um período de $24 \mathrm{~h} \pm 2 \mathrm{~h}$ e, em seguida, os tubos positivos, os quais apresentaram coloração amarelada, foram repicados para um meio de cultura específico (BBL ${ }^{\mathrm{Tm}}$ Bile Esculin Agar - Cat. No. 299068) para o crescimento do grupo Enterococcus spp às mesmas condições anteriores.

\section{Resultados e Discussão}

Para discussão dos dados não foram encontradas outras metodologias comparativas para análise concomitante ao estudo. Visto isso, foi realizada a discussão de acordo com os resultados obtidos neste experimento. Para análise dos dados, adotamos o período de estiagem nos meses de abril, maio, junho, julho, agosto e setembro. Para o período de maior vazão de águas e chuvas, adotamos os meses de outubro, novembro, dezembro, janeiro, fevereiro e março, meses estes que no Centro-Oeste são períodos registrados como chuvosos (HELLER; PÁDUA, 2006).

O gráfico 1 representa a média geral de todos os pontos coletados para E.coli e Enterococcus durante o período de junho de 2006 a maio de 2007, mostrando uma maior prevalência de E. coli em relação à Enterococcus neste período, não existindo diferença estatística entre o número de organismos E. coli isolados e o número de organismos Enterococcus isolados ( $\mathrm{p}=0,54)$. Em mais de $85 \%$ dos pontos coletados houve perda amostral. Por falta de meio de cultura, não foram realizadas análises de Enterococcus .

Verifica-se que no ponto de captação Alagado obteve-se resultados de $E$. coli e de Enterococcus altos. Neste período, iniciam-se as primeiras chuvas no Distrito Federal, nesta época, o maior pico foi de E. coli, no mês de novembro.

Os valores observados, no período da primavera, setembro a dezembro, início da estação chuvosa, seguida do verão, afirmam a possibilidade de um indicador poder ser favorecido pelo meio externo, como por exemplo, a chuva, que carreia sedimentos das margens para a captação, tornando-se assim uma fonte de alimentos extras aos microorganismos. 
No Barrocão, temos também uma coleta, onde prevalece a quantidade de Enterococcus. Observam-se níveis baixos de contaminação, tanto para Enterococcus quanto para E. coli. De acordo com a análise sazonal dos pontos de coleta, verifica-se que no mês de janeiro houve um pico de E. coli, quando oficialmente a estação chuvosa predomina, porém não podemos afirmar que, neste caso, a técnica que melhor avalia a contaminação é a Técnica do Susbtrato Enzimático, pois no mês de janeiro do ano de 2007, não foi realizada a análise para Enterococcus. Para todas as outras datas, sem dúvida, o melhor indicador é a E. coli, por se mostrar presente em grande quantidade na maioria das coletas.

Na captação Brejinho verificou-se, em algumas coletas realizadas, dois picos predominantes: o primeiro ocorreu em setembro de 2006 - início da primavera, quando se pôde relatar a ocorrência das primeiras chuvas, aumentando consideravelmente a população de E. coli; o segundo aconteceu, quando, já no término da primavera, em novembro de 2006, se constatou um crescimento populacional das colônias de Enterococcus, fato esse que se realiza pela presença de sedimentos provenientes do carreamento de matéria orgânica pela água das chuvas.

Já na captação Cabeça de Veado I, em 75\% das coletas realizadas, neste ponto para os dois indicadores, o resultado foi maior para Enterococcus, e somente $25 \%$ para E. coli. Verificou-se o maior pico populacional, no mês de outubro, quando houve um aumento considerável nas colônias de Enterococcus, sendo a estação predominante a primavera. Esse fato comprova o que alguns autores, já citados no texto, afirmam que o grupo Enterococcus é um bom indicador por se manter mais resistente às condições adversas do meio, persistindo mais no ambiente.

Na captação Cabeça de Veado II, há uma maior prevalência de E. coli (75\%) contra $25 \%$ de prevalência para Enterococcus. Com a estiagem predominante, de junho até metade de setembro, observou-se que, em agosto de 2006, os Enterococcus demonstraram-se como melhor indicador, sobrepondo-se ao valor de E. coli. Com o início das chuvas (segunda metade de setembro), o quadro mudou e a $E$. coli passou a ser um melhor indicador pelos seis meses seguintes, coincidindo com a estação da primavera - verão, quando o índice pluviométrico é alto, ocorrendo várias chuvas durante este período. 
A captação Cabeça de Veado III demonstrou valores para E. coli maiores que para Enterococcus, em todas as coletas realizadas. O maior pico observado nesta captação foi em outubro de 2006, quando o período de chuva estava predominante pela primavera. Com o início do verão, em dezembro de 2006, verificou-se uma queda abrupta na população de E. coli. Em abril de 2007, não houve detecção de índices de Enterococcus, no entanto, a E. coli se fez presente. Neste caso, o Enterococcus não se apresenta como o melhor indicador de contaminação fecal, independente da estação do ano em que foi realizada a coleta.

Em 75\% das análises realizadas para os dois indicadores, no ponto Cabeça de Veado IV, a prevalência de Enterococcus se fez presente. No período de estiagem, que acontece nos meses de junho, julho, agosto e metade de setembro, em 2006, a população de E. coli predominou apresentando-se como um indicador bom quanto às condições adversas neste período de estiagem. Com a mudança da estação do ano, a primavera vem acompanhada de chuvas e se inicia na metade de setembro, aumentando o índice de Enterococcus quase cinco vezes de agosto para outubro.

Cachoeirinha é uma captação onde são encontrados índices de indicadores sempre maiores para Enterococcus que para E. coli. Em setembro de 2006, com o início da primavera e conseqüente início das chuvas, este grupo se mostrou com um pico totalmente aparente de quase dez vezes. Em novembro do mesmo ano, os Enterococcus se mantiveram com um índice populacional alto em relação a E. coli, assim como em março de 2007. Tanto em época de estiagem, quanto em época chuvosa, os Enterococcus se apresentam como um ótimo indicador de contaminação fecal.

Na captação Capão da Onça, os resultados revelaram que, em aproximadamente 16\% das análises para os dois indicadores, houve ausência de Enterococcus na presença de E. coli. Em outra análise, realizada neste mesmo ponto de coleta, os Enterococcus se mostraram mais resistentes apenas na primeira coleta realizada, em junho de 2006. Em todas outras coletas, a E. coli demonstrou-se como melhor indicador, tanto em época de estiagem (junho a setembro) quanto no período primaveril (setembro a dezembro).

Nas coletas realizadas na captação Catetinho Baixo I, percebemos que a prevalência de Enterococcus é maior em todas as coletas realizadas no período de 
tempo deste estudo, exceto, na última coleta, onde a $E$. coli se apresentou com valor superior ao do Enterococcus. O maior pico durante a experimentação nesta captação foi no fim de setembro, quando a estação primaveril já estava oficialmente vigente.

Na captação Catetinho Baixo II, todas as coletas e análises realizadas para os dois indicadores, Enterococcus e E. coli, apresentaram-se prevalentes para Enterococcus, tanto em período de estiagem (julho a setembro) quanto em período de primavera. Ainda no ano de 2007, de janeiro a maio, quando a estação vigente é o verão e o outono, os Enterococcus se mantiveram em níveis detectáveis e maiores que a E. coli durante todo o experimento.

Nas coletas realizadas na captação Catetinho Nascente, o corpo d'água neste período esteve livre de contaminação fecal. Houve ausência tanto para $E$. coli como para Enterococcus, exceto, em uma análise na qual há a incidência de um E. coli em $100 \mathrm{ml}$ de amostra e outra na qual há a detecção de Enterococcus e ausência de E. coli. Esse ponto de captação está de acordo com a Portaria n ${ }^{\circ}$ 518/MS, que sugere uma ausência de bactérias indicadoras fecais na água tratada utilizada para o consumo humano, demonstrando a qualidade sanitária da água bruta (sem tratamento) deste ponto, independente da estação do ano vigente durante as coletas.

Na captação Contagem, observa-se ausência de Enterococcus e presença de E. coli. Análises individuais posteriores se mantiveram dentro dos padrões de normalidade conforme a Resolução CONAMA no 274/00 (Brasil, 2001). No começo do período de estiagem, em junho de 2006, a E. coli se apresentou como um ótimo indicador de contaminação fecal, assim como, no restante das coletas realizadas para o experimento. Verifica-se que tanto na época de seca, quanto na época de chuva, este se portou como o melhor indicador fecal, tendo uma elevação em sua quantidade populacional nos meses de outubro e dezembro de 2006, período este referente à estação da primavera, quando há uma maior ocorrência de chuvas e uma maior umidade.

Na captação Corguinho, observa-se que houve presença de E. coli na ausência de Enterococcus, indicando que, para este ponto, a E. coli é o melhor indicador de contaminação fecal do manancial. No período de estiagem, a $E$. 
coli se comportou aumentando a população de microorganismo, mesmo o ambiente sendo adverso para tal crescimento. Já nos meses de outubro e dezembro, verificou-se que, com o aumento das chuvas na época de primavera, seu valor aumentou com uma pequena queda em dezembro, porém voltou a subir no mês de abril de 2007.

Na captação Crispim, observa-se que a contagem de E. coli e de Enterococcus em uma coleta realizada houve uma maior detecção de Enterococcus. No período de estiagem, de acordo com o experimento, não podemos afirmar qual indicador é o mais eficaz, pois nesta época houve ausência (junho de 2006) ou incidência baixa (setembro de 2006). Porém com o aparecimento de chuvas, o indicador que melhor se adapta é o Enterococcus, tendo um pico no mês de novembro.

Em Engenho das Lajes, ocorreu uma detecção de níveis de contaminação fecal altos, havendo prevalência de Enterococcus no mês de setembro, quando houve uma ascensão abrupta do índice. A quantidade de E. coli aumentou ao longo do experimento, tornando-se a partir de novembro de $2006 \mathrm{um}$ bom indicador de contaminação fecal. O melhor indicador de contaminação fecal para esta captação é a E. coli por estar presente sempre em todas as análises efetuadas, independente de estiagem ou chuva.

Já na captação Fumal, onde obtivemos níveis altos de contaminação com prevalência para E. coli., houve um aumento considerável, em novembro de 2006, da quantidade de E. coli presente no corpo d'água quando a prevalência nesta captação é de $100 \%$ para E. coli. O índice de Enterococcus ao longo do experimento foi reduzindo, gradativamente, porém não houve detecção de ausência.

Na captação Mestre D’armas, todas as coletas realizadas, entre junho de 2006 e maio de 2007, obtiveram resultados maiores para todas as análises de Enterococcus, exceto, as coletas de agosto e dezembro de 2006, quando a E. coli se portou como melhor indicador. No período de estiagem, houve duas coletas e a E. coli se apresenta sem oscilação de valores, no entanto, quanto aos Enterococcus, há uma pequena queda na quantidade populacional, seguida de uma ascensão no período primaveril, em outubro de 2006. Com relação a E. coli, há um aumento populacional, em dezembro, com o início do verão, seguido de uma 
queda. Neste caso específico da captação, 60\% das análises favorecem os Enterococcus, tornando-o o melhor indicador para este caso.

Em Olhos d'água, há ausência de Enterococcus e há presença de E. coli, em mais de $50 \%$ das análises realizadas. O período de estiagem demonstra que os indicadores, mesmo em condições adversas do meio, detectaram índices de contaminação fecal, ainda que baixos. Em setembro de 2006 e maio de 2007, houve a detecção de E. coli com ausência de Enterococcus, favorecendo assim a E. coli como um bom indicador de contaminação fecal. Em novembro de 2006, houve um pico populacional de microorganismos do grupo coliforme fecal, cujo representante nas análises realizadas é a $E$. coli.

Assim, como na captação Olhos d'água, na captação Paranoazinho verifica-se que, em $60 \%$ das coletas realizadas, não houve detecção de índices de Enterococcus com E. coli presente. Em outubro do ano de 2006, observamos que ocorreu um pico, provavelmente, proveniente da ação das águas da chuva do período primaveril, que por meio do sedimento presente no fundo dos rios e às margens dos mesmos, aumenta a quantidade de matéria orgânica. Nestes pontos, observamos visivelmente a prevalência de E. coli, sendo este o indicador que melhor avalia a contaminação fecal humana.

Em Pedras, verifica-se uma oscilação muito diversa entre os indicadores de contaminação fecal. No período de estiagem, período este que abrange os meses de junho, julho e setembro de 2006, a prevalência foi para Enterococcus. Porém, com a chegada da primavera no fim de setembro e a conseqüente chegada das precipitações, o valor populacional da E. coli aumenta, sendo mais prevalente neste período, até o fim da estação. Quanto ao valor de Enterococcus, decaindo durante a estação chuvosa, percebe-se que ele ainda se fez presente neste período, exceto em janeiro de 2007, que por falta de meio de cultura, não foi possível a realização da análise.

Em Pipiripau, há prevalência absoluta de Enterococcus. Todas as coletas realizadas para os dois indicadores correspondem a um maior número de bactérias deste grupo, não sendo excluída a presença de E. coli. Esta captação é a que melhor representa o Enterococcus como indicador de contaminação fecal. No período de estiagem, entre os meses de julho e setembro de 2006, o Enterococ- 
cus, por serem mais persistentes ao meio ambiente e às condições adversas, permaneceu com índices de contaminação altos. Fato esse que se repetiu no período chuvoso, início do verão, no mês de dezembro de 2006.

Em Ponte de Terra I, Ponte de Terra II e Ponte de Terra III, há um equilíbrio qualitativo dos indicadores, onde há a prevalência de Enterococcus, porém a média não condiz com a prevalência, pois foram encontrados valores altos para E. coli. Os gráficos destas captações são relativamente parecidos, por serem captações provenientes de um mesmo manancial com coletas em pontos distintos, seguidos de captações distintas. Houve nas três captações, no mês de novembro, após o início das chuvas, um pico populacional dos dois indicadores o que nos sugere uma contaminação.

Na captação Quinze, há a prevalência maior de E. coli nas análises realizadas. No período de estiagem, que vai de julho até metade de setembro de 2006, verificou-se que a $E$. coli se comportou melhor às condições adversas do meio externo que o Enterococcus, porém em novembro do mesmo ano, houve um aumento do índice de contaminação dos Enterococcus, devido provavelmente ao aparecimento de precipitações e à estação climática vigente.

Na captação Taquari, há prevalência para Enterococcus, e percebe-se que no período de estiagem e metade do período chuvoso, o Enterococcus se faz presente em maior quantidade, tendo um pico em novembro, mês em que a estação vigente é a primavera, estação chuvosa.

Já na captação Torto, no período de estiagem que vai de julho a metade setembro, percebe-se que o Enterococcus tem um comportamento melhor que a E. coli, persistindo mais no meio ambiente. No período chuvoso, referente ao mês de novembro de 2006, houve um pico de E. coli e uma queda no índice de Enterococcus.

Com a queda da chuva nos solos adjacentes aos mananciais, há possibilidade de toda a matéria orgânica ali presente, antes somente nas margens, ter escorrido e se alocado nas águas dos rios. O impacto desta água pluvial nas corredeiras redistribuindo a matéria orgânica presente no fundo dos rios alimenta primordialmente as bactérias existentes (RIGOBELO; NAHAS, 2004). 


\section{CONCLUSÃO}

Os mananciais do Distrito Federal são importantes pelo fato de abastecerem a população, por isso sua importância é maior quando falamos de saúde pública, pois uma água contaminada na fonte gera um custo maior para o tratamento, e um conseqüente custo para o consumidor/usuário. Os resultados encontrados atenderam aos objetivos propostos no presente estudo, pois demonstram que o Enterococcus pode ser utilizado como indicador de contaminação fecal tanto quanto a E. coli. A agência sanitária dos Estados Unidos da América (U.S Environmental Protection Agency), após vários estudos realizados para analisar qual indicador tem a mesma valia que os coliformes determinou os Enterococcus como indicador de contaminação fecal, incluindo-o na planilha de análises da qualidade da água, desde 1986. Para melhoria do monitoramento da qualidade da água, a implantação da metodologia para detecção de Enterococcus pode ser utilizada complementarmente aos testes atualmente adotados, visto que sua detecção de contaminação fecal associada à E. coli proporciona melhor controle da qualidade da água distribuída à população. A análise sazonal também é um bom artifício indicador da contaminação, pois percebemos a susceptibilidade dos indicadores às condições adversas do meio ambiente. Em suma, para se obter um bom indicador, não basta avaliar somente o microorganismo em si. Seus mecanismos de defesa, também, têm de ser avaliados para garantir um tratamento adequado para sua distribuição à população.

\section{Seasonal profiling of Enterococcus and E. Coli in water source of Distrito Federal}

\section{Abstract}

To certify the quality of the water, the right choice of the microbiological indicator for detection of minimum levels of contamination is essential, that is why the sensibility and the specificity are one of the criteria used for its choice. The most usual indicator in the laboratories is the E. coli. The major point in this report is analyze the values obtained through the technique of the enzymatic for E. coli substrate and the technique of the multiple pipes the Enterococcus, which are more persistent in the environment and compares those results to the values of for Some 
values showed that Enterococcus were more resistant to the action of the environment, others values showed that $E$. coli were more resistant despite the conclusion does not apoint to a method more effective than other. The seasonal evaluation determines when we can use the pointers due to the adversities of the way and allow more security to the quality of the water and, consequently to human health.

Keywords: Water resourses. Ambiental microbiology. Enterococcus.

\section{Referências}

AMERICAN PUBLIC HEALTH ASSOCIATION. Standard methods for the examination of water and wastewater. 21. ed. Washington: APHA/WEF/AWWA, 2005.

AUGUSTO, L. G. S. Saúde e vigilância ambiental: um tema em construção. Departamento de estudos em saúde pública. Epidemiologia e serviços em saúde, Brasília, v. 12, n. 4, p. 177-187, 2003.

BRASIL, Ministério do Meio Ambiente, Conselho Nacional do Meio Ambiente. Resolução no 274, de 29 de novembro de 2000. Diário Oficial da República Federativa do Brasil. Seção 2. Brasília, DF, 25 de janeiro de 2001. 2001

BRASIL. Ministério do Meio Ambiente. CONAMA RESOLUÇÃO 357/05. Brasília, DF, 2005.

BRASÍLIA - DF. Companhia de Saneamento Ambiental do Distrito Federal CAESB. Programa de Proteção das Captações. Disponível em: <http://www. caesb.df.gov.br>. Acesso em: 27 abr. 2006.

BRASİLIA - DF. Secretaria de Meio Ambiente e Recursos Hídricos do Distrito Federal. Os recursos hídricos no Distrito Federal Disponível em: <http://www. semarh.df.gov.br>. Acesso em: 11 maio 2006.

BUCK, J. D. Ocurrence of false positive most probable number test for fecal streptococci in marine water. American Society of Microbiology. Estados Unidos da América, v. 18, n. 10, p 562-565, 1969.

FIGUEIRAS, M. J. et al. A fast method for the confirmation of fecal streptococci from M-Enterococcus medium. American Society of Microbiology, Espanha, v. 62, n. 6, p. 2177-2178, 1996. 
FREITAS, M. B; BRILHANTE, O. M.; ALMEIDA, L. M. Importância da análise de água para a saúde pública em duas regiões do Estado do Rio de Janeiro: enfoque para coliformes fecais, nitrato e alumínio. Cadernos de Saúde Pública, Rio de Janeiro, v. 17, n. 3, p. 651-660, 2001.

HACHICH, E. M. et al. Análises microbiológicas da água. São Paulo: CETESB, 2000 .

HELLER, L; PÁDUA, V. L. Abastecimento de água para consumo humano. Belo Horizonte: UFMG, 2006.

INSTITUTO BRASILEIRO DE GEOGRAFIA E ESTATÍSTICA - IBGE. Banco de dados por estado. Disponível em: <www.ibge.gov.br >. Acesso em: 15 mar. 2007.

LITSKY, W; ROSEBAUM, M. J.; FRANCE, R. L. A comparision of the most problable number of coliform bacteria and enterococci in raw sewage. American Society of Microbiology, Estados Unidos da América, v. 20, n. 10, p. 247-250, 1953.

MESSER, J. W.; DUFOR, A. P. A rapid specific membrane filtration procedure for enumeration of enterococci en recreational water. American Society of Microbiology, Estados Unidos da América, v. 64, n. 2, p.678-688, 1998.

RIGOBELO, E. D.; NAHAS, E. Flutuação sazonal da comunidade bacteriana e da atividade microbiana em solos sob euaclipto e pinus. Scientia Agricola, Piracicaba, v. 61, n. 1, p.83-93, 2004.

TORTORA, G. J.; FUNKE, B. R.; CASE, C. L. Microbiologia. 9. ed. Porto Alegre: Artmed, 2002.

VON SPERLING, M. Introdução à qualidade das águas e ao tratamento de esgotos. 2. ed. Belo Horizonte: Departamento de Engenharia Sanitária e Ambiental, Universidade Federal de Minas Gerais, 1996. v. 1.

YOSHPE-PUSER, Y. Evaluation of media for monitoring fecal Streptococci in seawater. American Society of Microbiology, Israel, v. 55, n. 8, p. 2041-2045, 1989. 